\title{
Farmer's lung after Mycoplasma pneumoniae infection
}

\author{
CLIVE McGAVIN \\ From Plymouth Chest Clinic, Plymouth
}

Farmer's lung is a hypersensitivity reaction to fungal spores in mouldy hay, most commonly Micropolyspora faeni. The type of immunological reaction is debated ${ }^{1}$ but a high dose of antigen is necessary and the inflammation may result from activation of the alternative pathway of complement, linked to a type 3 response. Detection of serum precipitins to fungal antigens is used as a diagnostic aid but it is unclear why up to $18 \%$ of men with sufficient exposure to antigen and with the serum precipitins do not develop symptoms. ${ }^{2}$ Two Cornish men are described who had long term exposure to dusty hay but who developed symptoms of farmer's lung only after infection with Mycoplasma pneumoniae.

\section{Case reports}

CASE 1

A 31 year old non-smoking farmer presented in January 1979 with an acute febrile illness associated with cough, sputum, headache, and extensive lung crackles. He had had no symptoms of farmer's lung before 1979 despite years of handling hay. At presentation his chest radiograph showed bilateral consolidation and the titre of antibody to Myco pneumoniae in the complement fixation test ${ }^{3}$ was $1 / 320$. After one month, during which he had avoided hay and taken tetracycline, he was still unwell and breathless. The Myco pneumoniae antibody titre in the complement fixation test had risen to $1 / 1280$ and the precipitin test for $M$ faeni measured by a double diffusion technique ${ }^{4}$ gave a strongly positive result. He was admitted to hospital and treated with prednisolone and erythromycin. He improved over a fortnight and was discharged from hospital. One month after discharge, while still taking prednisolone $10 \mathrm{mg}$ daily, he spent a day working in a barn in which the winter's hay had been stored. That evening he developed fever, breathlessness, and headache and was readmitted with a diagnosis of acute farmer's lung. Again he improved gradually with increased doses of corticosteroids. By August 1979 the drugs had been withdrawn, the chest radiograph was normal, but the single breath carbon monoxide transfer factor (TLCO) was $76 \%$ predicted. He has since avoided contact with hay and remained symptom free. In April 1981 a complement fixation test for Myco pneumoniae showed a titre of only $1 / 40$ but the result of the $M$ faeni precipitin test remained strongly positive.

\section{CASE 2}

This $\mathbf{4 0}$ year old farmer had also handled hay for many years with impunity; in particular, the harvest of 1980 had produced dusty hay but he did not develop symptoms of hyper-

Address for reprint requests: Dr Clive McGavin, Plymouth Chest Clinic, Beaumont Park, Plymouth PL4 9BQ.

Accepted 30 August 1985 sensitivity in the following winter. In December 1981 he developed pneumonia. The Myco pneumoniae complement fixation test gave a positive result with a titre of $1 / 1280$ and the result of the precipitin test against $M$ faeni was strongly positive. Despite treatment with tetracycline and corticosteroids and advice to avoid hay he remained breathless for several months. In May 1982 his Myco pneumoniae antibody titre had fallen to $1 / 80$. By May 1983 he had recovered fully with no residual lung crackles and his carbon monoxide transfer factor (TLCO) was $70 \%$ of the predicted value. In December he had a brief exposure to dusty hay while opening a new rick containing mouldy bales. That night he developed symptoms of acute farmer's lung. When seen eight weeks later he was still breathless with extensive lung crackles. The Myco pneumoniae antibody titre in the complement fixation test was $1 / 160$ and precipitins against $M$ faeni remained strongly positive. Again he made a slow recovery over several months.

\section{Discussion}

These cases have features in common. Neither man had symptoms of farmer's lung before the infection with $\mathrm{Myco}$ pneumoniae despite years of handling hay; it is reasonable to suggest that the precipitins against $M$ faeni were present before the mycoplasma infection because they remained strongly positive subsequently while the Myco pneumoniae antibody titre in the complement fixation test waned. Both men had acute respiratory illnesses with clinical and serological features of Myco pneumoniae infection but, interestingly, the delayed recovery over several months was typical of neither mycoplasma infection nor acute farmer's lung. Both men developed acute respiratory illnesses when exposed to hay dust after the mycoplasma infections; these illnesses more closely resembled acute farmer's lung than pulmonary mycotoxicosis ${ }^{5}$ in that both men had precipitins to $M$ faeni and neither had had a heavy exposure to spores in a confined space such as a silo.

In 1975 Davies et $a l^{6}$ reported the development of IgG antibodies against $M$ faeni in two patients with severe $M y c o$ pneumoniae infection without exposure to mouldy hay. They described a polysaccharide surface antigen common to the Mycoplasma and the Micropolyspora spores. Possibly the presence of anti-Mycoplasma antibodies in the two farmers caused an enhanced reaction to fungal spores by the activation of the alternative pathway of complement. It is also possible that the mycoplasma infection produced a nonspecific increase in levels of complement and acute phase proteins in the lung, and hence a non-specifically enhanced reaction to subsequent inhalation of fungal antigen.

I acknowledge the advice of Dr Alex Ferguson and Dr Brian Davies and the secretarial assistance of Miss Joan Mitchell 


\section{References}

1 Emanuel DA, Kryda MJ. Farmer's lung disease. Clin Rev Allergy 1983;1:509-32.

2 Pepys J, Jenkins PA. Precipitin (FLH) tests in farmer's lung. Thorax 1965;20:21-35.

3 Bradstreet CMP, Taylor CED. Technique of complement fixation test applicable to the diagnosis of virus disease. Monthly Bulletin of the Ministry of Health and PHLS 1962;21:96.

4 Mackenzie DWR, Proctor AGJ, Philpot CM. Basic serodiagnostic methods for disease caused by fungi and actinomycetes. London: HMSO, 1980. (PHLS monograph No 12.)

5 Emanuel DA, Wenzel FJ, Lawton BR. Pulmonary mycotoxicosis. Chest 1975;67:293-7.

6 Davies BH, Edwards JH, Seaton A. Cross-reacting antibodies to Micropolyspora faeni in Mycoplasma pneumoniae infection. Clin Allergy 1975;5:217-24.

\section{Book notices}

Clinical Tests of Respiratory Function. GJ Gibson. (Pp 334; £30.) Macmillan Press. 1984.

Physicians interested in the better practice of modern respiratory medicine now have a plethora of textbooks from which to make a selection for their departmental or hospital libraries or for the more immediately accessible personal bookshelf. Clinical Tests of Respiratory Function is a welcome addition, with its greater emphasis on clinical application and lung function complements, without displacing the more laboratory based text of John Cotes. The author correctly observes that tests of respiratory function are not fully integrated into clinical medicine. The requirements for horacic medicine published in Thorax (1984;39:400) recon mended that inpatients and outpatients should have ready access to a respiratory physiology laboratory staffed by trained technicians. Such a book as this will be invaluable to those doctors concerned in establishing these departments. The text, after a brief description of the apparatus, is divided into three main sections describing, firstly, the theoretical and practical aspects of the commonly applied tests of mechanical and gas exchange function, respiratory control and exercise; secondly, functional alterations in conditions traditionally encompassed by the respiratory physician, such as airway, alveolar, and pleural diseases; and, thirdly, respiratory impairment in diseases of other systems, such as renal, hepatic, metabolic, and connective tissue disorders. I believe that this book will be invaluable to respiratory physicians with either a mainstream or a more peripheral interest in the practical application of clinical respiratory physiology. The text merits better quality paper and printing, a message which might usefully be conveyed to the publisher in time for the second edition.-RMC

Esophageal Disorders-Pathophysiology and Therapy. Tom R DeMeester, David B Skinner. (Pp 655; \$13.) Raven Press. 1985.

This is a multiauthor publication appearing some two years after the Second International Symposium on Oesophageal Disorders held in Chicago in 1983. The papers are generally well written but the presentation of data, the tables, and the graphics are at times of poor construction and fail to give credit to the fine text. The main topics covered in this book include oesophageal physiology, in particular a definitive histological study of nerve and muscle from James Christensen; radionuclide imaging; reflux and its complications; carcinoma; and the functional oesophageal disorders. There is little emphasis on oesophageal varices and atresia. Nearly one third of this 655 page book is devoted to 24 hour $\mathrm{pH}$ monitoring. There is far too much overlap, with a grand total of 28 chapters adding little to the previously published works of Johnson and DeMeester. Although this section suffers in particular from the time lag between conference and publication, for those wishing to undertake $\mathrm{pH}$ monitoring it is a comprehensive and valuable guide to the techniques and equipment available.-IPA

Respiratory Care. Edited by George G Burton and John E Hodgkin. 2nd ed. (Pp 1071; £47.) JB Lippincott Company. 1984

Fifty four authors, most medically qualified, contribute to this comprehensive and readable textbook for American respiratory care technicians. Section 1 deals with the evolution of that profession, its training programmes, competency assurance procedures, ethics, and relationships with other professions. The chapter on legal implications of respiratory care has a six page glossary of legal terms, and there is a chapter on contemporary issues in health ethics. Section 2 , on the rational basis of respiratory therapy techniques, includes conventional accounts of lung physiology, lung function testing, clinical examination, and interpretation of chest radiographs, and highly technical chapters on medical gases (manufacture, storage, transport) and aerosols (28 equations on the relevant physics). The account of oxygen therapy does not mention its eupnogenic effect. Therapeutics have a transatlantic slant-for example "The basic drug in managing chronic asthma is theophylline." Intermittent positive pressure breathing is discussed sceptically and admitted to be "the ideal placebo." Section 3 deals with respiratory care in critical illness. The book is too long and detailed for medical students, nurses, and physiotherapists, and too superficial in its clinical aspects for chest doctors. In short, it is an excellent book aimed at a readership which does not really exist in the United Kingdom.-CS 